\title{
Enhancing a Junior Level Materials Lab with SEM Iimages
}

\author{
Dr. Aezeden Mohamed, EIT. \\ Dept. of Mechanical and Manufacturing \\ University of Manitoba, \\ Canada, R3T 5V6 \\ Aezeden@cc.umanitoba.ca
}

\begin{abstract}
Lab courses can enhance a student's communication skills, provide opportunities to practice team work, and raise self-confidence early in their university experience, as well as impart valuable technical knowledge. Students ran impact Charpy tests on alloy steel 1045, and aluminum alloy 6061 as a function of temperature, and then analyzed and investigated by unaided eye the fracture surface in the two alloys at the macro-scale level. In this paper, micro-scale level investigation by the scanning electron microscopy (SEM) images introduced for the first time in this context to enhanced junior level materials lab.
\end{abstract}

Keywords: Students: SEM images: alloy steel 1045; aluminum alloy 6061; fracture surface.

\section{Introduction}

The course, MME 25.227, Principles of Materials Sciences and Engineering, is offered every year at the University of Manitoba. The maximum class size is 80 students who participate in two sections and four lab sessions, with 20 students per lab session. The various kinds of testing are considered on the materials in this course include hardness, tensile, fatigue, and impact tests. Classes are held in the lecture theatre twice a week and supported by PowerPoint presentations. Students also attend a three hour lab session once a week where they interact with a teaching assistant.

Students are exposed early in their education to understand differences between the crystal structures of materials, such as steel and aluminum, and to observe how fracture behaviour varies with temperature (Ambrose 1997). When fractures occur in steel structures, the most dramatic and unexpected cause of brittle failure is their tendency to loose almost all of their toughness when the temperature drops below the ductile to brittle transition temperature (Shank 1953) and (ASM 1985). This has been the cause of numerous dramatic and catastrophic failures

\author{
Dr. Ron Britton \\ Eng.Associate Dean (Design Education) \\ University of Manitoba, \\ Canada, R3T 5V6 \\ ron_britton@umanitoba.ca
}

(ASTM 1984). With a simple impact test students are able to determine the reason for such failures. Students see through demonstration, that choosing the right material for the environment is essential for avoiding catastrophic failure in structures and resulting human loss.

In the past years the impact test was used in this laboratory are evaluations of energy absorbed as a function of temperature and for investigating fracture surfaces by unaided eye. In this paper, in addition to this macro-scale level, the students are introduced to the micro-scale level through SEM images for deeper understanding of the internal changes behind the macro-scale fracture surfaces in impact tested of steel and aluminum.

\section{Material sand Experimental Procedures}

The chemical composition (wt.\%) of 1045 alloy steel is $(0.43-0.50 \% \mathrm{C}, 0.60-0.90 \% \mathrm{Mn}, 0.050 \% \mathrm{P}, 0.050 \% \mathrm{~S})$ and aluminum alloy $6061(0.40-0.80 \% \mathrm{Si}, 0.70 \% \mathrm{Fe}$, $0.15-0.40 \% \mathrm{Cu}, \quad 0.15 \% \mathrm{Mn}, \quad 0.80-1.20 \% \mathrm{Mg}, \quad 0.04-$ 0.35\%Cr, $\quad 0.25 \% \mathrm{Zn}, \quad 0.15 \% \mathrm{Ti})$. V-notch Charpy specimens were machined according to ASTM (E-2393 1993) as shown in Figure 1.

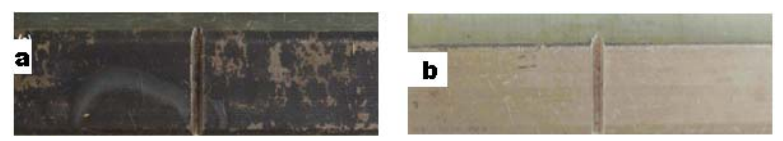

Figure 1: V-notch Charpy specimens (a) steel and (b) aluminum were machined according to ASTM (E-23-93 1993).

\subsection{Impact test}

Specimens of both materials were tested at seven different temperatures. The required temperatures were obtained by immersing specimens in different environments as shown in Table 1. 
Table 1: showing environments of the seven specimens tested at specific temperatures

\begin{tabular}{|c|c|c|}
\hline $\begin{array}{l}\text { Test } \\
\text { No. }\end{array}$ & Environments & $\begin{array}{c}\text { Temperature } \\
\left({ }^{\circ} \mathrm{C}\right)\end{array}$ \\
\hline 1 & Liquid $\mathrm{N}_{2}$ & -200 \\
\hline 2 & Liquid $\mathrm{N}_{2}+$ Alcohol & -80 \\
\hline 3 & Dry ice +Alcohol & -60 \\
\hline 4 & Ordinary ice & 0.0 \\
\hline 5 & Room temperature & +24 \\
\hline 6 & Warmer water & +60 \\
\hline 7 & Boiling water & +100 \\
\hline
\end{tabular}

The specimens were removed from the temperature bath and rapidly secured into the test fixture of the impact machine and followed by release of the impact force. The energy absorbed by the specimen to failure was directly read from the graduated scale on the test machine. Data were plotted to produce a relation between temperature and energy absorbed as shown in Figure 2.

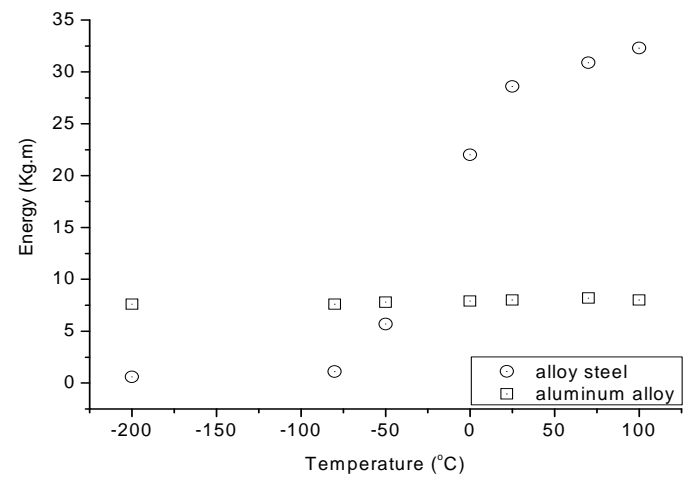

Figure 2: Effect of temperature on Charpy impact test.

From these plots students can easily observe that aluminum curve remains level through the entire 7 test environments, whereas the steel 1045 curve shows extreme change with temperature over three regions. An upper plateau occurs at high temperature with ductile-like fracture, a lower plateau at low temperature with brittle-like fracture, and the third region, a mixture of both regions and a transition region, in which the fracture surface is a brittle-ductile fracture.

After the fourteen Charpy steel and aluminum specimens were fractured, specimens were collected and kept for further detailed observations as shown in Figure 3 and Figure 4. Once students completed testing the fourteen test specimens of steel 1045 and aluminum 6061 were observed by the students with the help of the Teaching Assistant. Comparisons were made between the characteristics of the fracture surfaces and the test temperature of each material and between steel and aluminum at the same temperature. Specimens of steel 1045 fracture into pieces as the temperature decreases below zero and show brittlelike fracture (specimens 1 to 4 from $-200 \mathrm{oC}$ to $0.0 \mathrm{oC}$ ), whereas specimens exhibited ductile like fracture as the temperature increased (specimens 5 to 7 from $24 \mathrm{oC}$ to $100 \mathrm{oC}$ ). Specimen number 4 impacted at $0.0 \mathrm{oC}$ seem to have a combination of both brittle and ductile fracture modes as shown in Figure 3. For aluminum 6061 all 7 specimens did not fracture into two pieces which means this materials impact behaviour is independent of temperature and therefore dislocation motion is almost independent of temperature. The fracture surface appears as a ductilelike fracture, as shown in Figure 4. It was clear that all 7 aluminum specimens were buckling from both sides, this indicating that there is strong resistance to fracture into two pieces as show in Figure 4. However, the fracture type for steel 1045 is very strongly dependent on temperature, as shown in Figure 3.

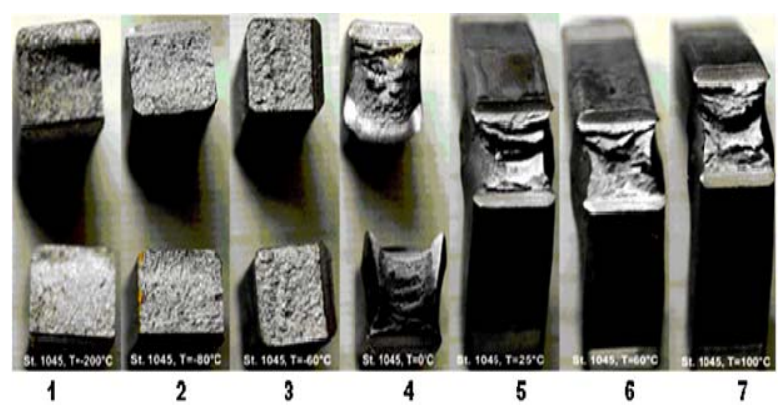

Figure 3: Fracture surfaces of Charpy alloy steel 1045 specimens at seven different temperatures.

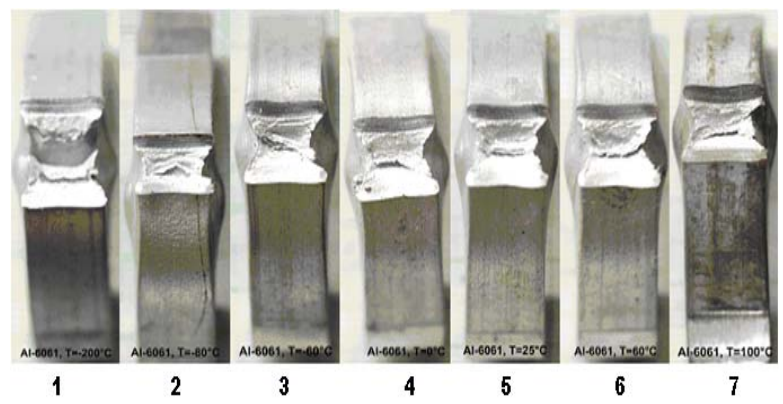

Figure 4: Fracture surfaces of Charpy aluminum alloy 6061 specimens at seven different temperatures. 


\subsection{Failure analysis}

The Teaching Assistant ran a trial test prior to the student laboratory session to examine the fracture surfaces of test specimens in a scanning electron microscope (SEM) for macroscopic fracture mode and to characterize the fine-scale topography and microscopic mechanisms governing fracture. The distinction between the macroscopic mode and microscopic fracture mechanism is based entirely on the magnification level at which the observations are made. In this context, the macroscopic mode refers to the nature of failure as shown in Figures 2-4, while the microscopic mechanisms relate essentially to the local failure processes as shown in Figures 5 to 11. SEM analyses were obtained from the top fracture zone.

\section{Results and Discussion}

The amount of energy absorbed by alloy steel 1045 decreases with a decrease in test temperature, as shown in Figure 2. This was especially exhibited in the alloy steel 1045. The curve of alloy steel 1045 is essentially divided into three regions, aluminum alloy 6061 shows almost no change with temperature, as shown in Figure 2. In region 1, stable crack propagation occurs, culminating in failure by cleavage. This region is the lower plateau region of specimens 1 to 3, as shown in Figure 3. In region 2, the energy absorbed, or toughness of the material, increases linearly with an increase in test temperature and is sometimes called the transition region. Such an increase can be attributed to an increase in localized microscopic plasticity ahead of the propagating crack front and the concomitant intrinsic micromechanisms governing fracture. In region 3 , referred to as the upper plateau, the high-energy absorption capability is ascribed to fracture by ductile tearing and observed in specimens 6 and 7, as shown in Figure 3. The curve of aluminum 6061 plateaus from specimens 1 to 7 with almost no change with temperature, as shown in Figure 2.

The essential difference between region 2 and region 3 is the amount of tearing associated with ductile failure. A design requirement that emphasizes the need for dynamic upper plateau behaviour at a particular temperature will also ensure a similar static response at the same temperature. Scanning electron micrographs shown in Figure 5 support the observations made from measurement of energy absorbed during impact as a function of temperature. The fracture surface features associated with the specimen dynamically deformed at $-200^{\circ} \mathrm{C}$ are shown in Figure 5.
The majority of the fracture surface reveals failure of the sample to be essentially brittle with the occurrence and presence of cleavage facets. The transgranular cleavage facets are representative of unstable crack propagation along specific crystallographic planes. The fracture surface appeared flat and nearly featureless. Intersection of the propagating crack with the grain boundary causes the crack path to change direction in the neighbouring grain. Growth of the cleavage cracks on parallel crystallographic planes causes them to overlap and appear as steps as seen in Figure 5 (a). The cleavage facets are essentially flat as in Figure 5 (a). Aluminum 6061 shows dimples and a dull fracture (Figure 5 (b)).
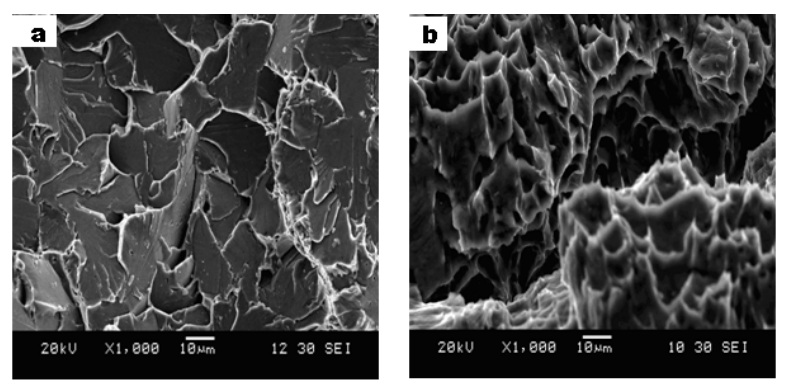

Figure 5: SEM images of fracture surfaces at $-200^{\circ} \mathrm{C}$ (a) steel 1045 showing cleavage fracture with deep secondary cracking, river patterns and cleavage facet (b) aluminum 6061 showing dimples.

The characteristics of brittle fracture along secondary cracking are shown in Figure 6 (a) whereas aluminum shows ductile fracture (Figure 6 (b)).
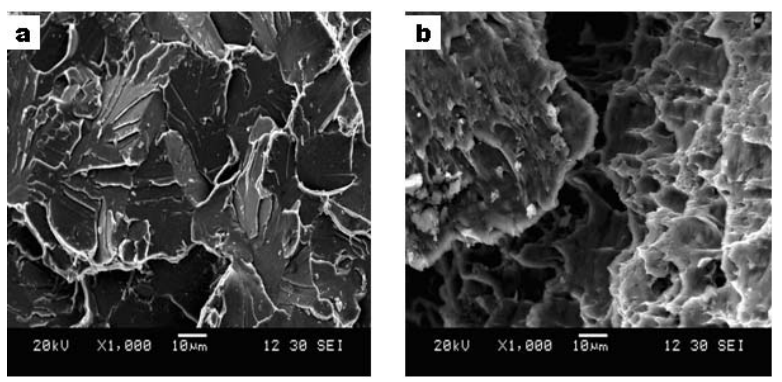

Figure 6: SEM images of fracture surfaces at $-80^{\circ} \mathrm{C}$ (a) steel 1045 showing transgranular cleavage facet (b) aluminum 6061 showing dimples on both sides of the fracture.

The fracture surface features of the Charpy specimens dynamically deformed at $-60^{\circ} \mathrm{C}$ are shown in Figure 7 . Fracture was essentially transgranular cleavage. High magnification observations revealed pockets of shallow dimples adjacent to the grain boundaries, features reminiscent of locally ductile failure, as in Figure 7 (a). The presence of some ductile fracture indicates the initiation of localized mixed-mode 
behaviour may start facilitating a transition in macroscopic response. The energy absorbed at $-60^{\circ} \mathrm{C}$ is about five times greater than the energy absorbed by the specimen deformed at $-200^{\circ} \mathrm{C}$. Figure 7 (b) show similar feature as in Figures 5 (b) and 6 (b).
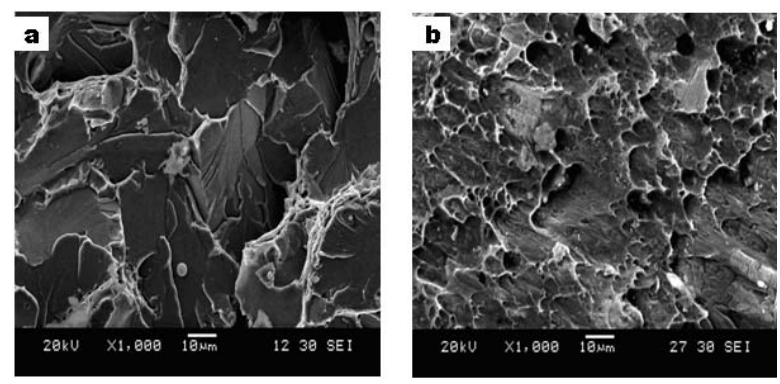

Figure 7: SEM images of fracture surfaces at $-60^{\circ} \mathrm{C}$ (a) steel 1045 showing transgranular cleavage facet and shallow dimples adjacent to the grain boundaries (b) aluminum 6061 showing dimples along with fracture direction.

Fracture features of the Charpy specimen deformed at $0^{\circ} \mathrm{C}$ are shown in Figure 8. Unlike the Charpy specimens 1,2 and 3 deformed at $-200,-80$ and $-60^{\circ} \mathrm{C}$, respectively, the fracture surface revealed mixed-mode fracture with locally brittle and ductile failure.
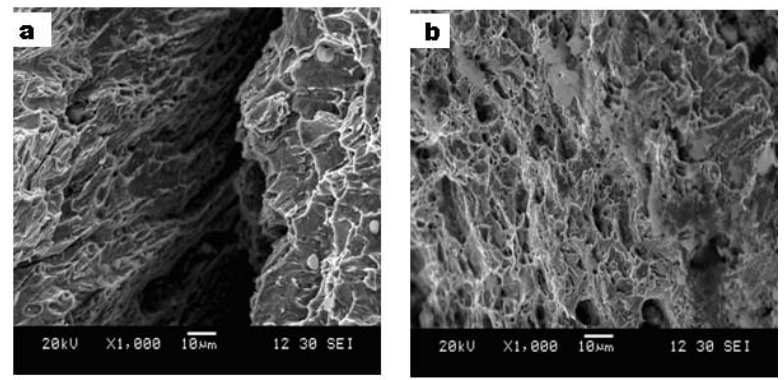

Figure 8: SEM images of fracture surfaces at $0^{\circ} \mathrm{C}$ (a) steel 1045 showing mixed cleavage and ductile tearing, featureless cleavage (b) aluminum 6061 showing dimples and high population of microvoids

Figure 9 (a) reveals fracture surface with isolated pockets of voids and shallow dimples. On account of the dynamic nature of loading and the resultant rapid propagation of the crack through the microstructure, the growth and coalescence of the microscopic voids exert little influence on the fracture process. On average, the energy absorbed by the specimen is nearly 30 times higher than for the samples deformed at the lowest temperature $\left(-200^{\circ} \mathrm{C}\right)$. In Figure 9 (b) the aluminum 6061 exhibits dimples, microviods, and some serration due to dynamic deformation.

The drastic change in toughness is indicative of the transition temperature region of the upper plateau impact toughness curve. For steel 1045, specimen 6, impacted at $60^{\circ} \mathrm{C}$, the fracture surface exhibits denser microvoids and dimples. No evidence of cleavage or sign of brittle fracture is observed in (Figure 10 (a)). The fracture surface of alloy steel 1045 behaves similarly to aluminum 6061 specimen as shown in Figure 10 (b). This is due to the steel alloy at high temperature behaving in similar manner to the aluminum alloy.
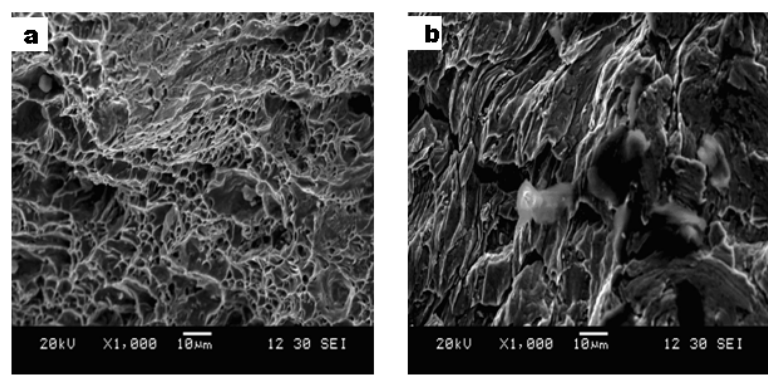

Figure 9: SEM images of fracture surfaces at $25^{\circ} \mathrm{C}$ (a) steel 1045 showing dimples and some cleavage (b) aluminum 6061 showing dimples and microvoids.
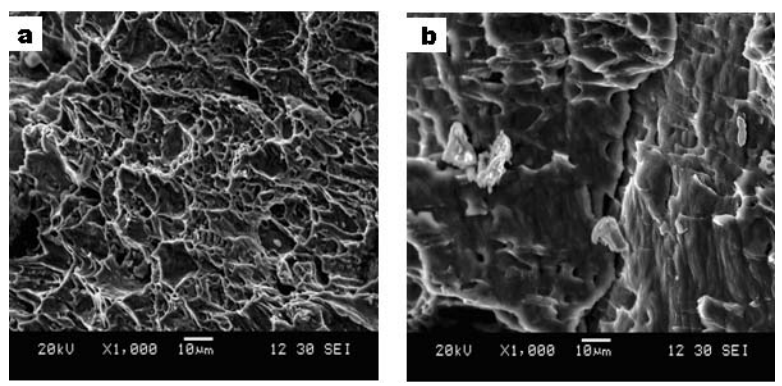

Figure 10: SEM images of fracture surfaces at $60^{\circ} \mathrm{C}$ (a) steel alloy 1045 showing dimples and ductile tearing, featureless cleavage (b) aluminum 6061showing dimples and high population of microvoids.

For specimen 7 impacted at $100^{\circ} \mathrm{C}$, the fracture surface shows the regions immediately adjacent to the intergranular fracture and revealed ductile tear ridges comprising a population of microscopic voids and shallow dimples, features reminiscent of locally ductile failure, as shown in Figure 11 (a).

Microscopic void initiation occurred at the coarse second-phase particles both at and along the grain boundary region. As the amount of microscopic voids and dimples on the fracture surfaces increases, the total energy absorbed to fracture increases. The average energy absorbed during impact at this test temperature is about $35 \mathrm{Kg} . \mathrm{m}$, whereas the energy absorbed by the specimen dynamically deformed at the lowest temperature $\left(-200^{\circ} \mathrm{C}\right)$ is about $2 \mathrm{Kg} . \mathrm{m}$.

The fracture surface features observed for the Charpy specimen deformed at $100^{\circ} \mathrm{C}$ are shown in Figure 11. 
Fracture was essentially rough at the microscopic level with an absence of cleavage facets (Figure 11 (b)). The fracture surface was covered with a population of voids and dimples (Figure 11 (b)). Such observations are consistent with the upper plateau behaviour of alloy steel 1045 having near similar composition and strength. The fracture surface also revealed numerous secondary cracks (Figure 11 (a)). High magnification observations of the transgranular fracture surface revealed voids and elongated dimples in both steel and aluminum, as shown in Figure 11 (a) and (b). Elongation of the dimples may be from the occurrence of ductile shear failure. The region of ductile tearing revealed microscopic voids and dimples.
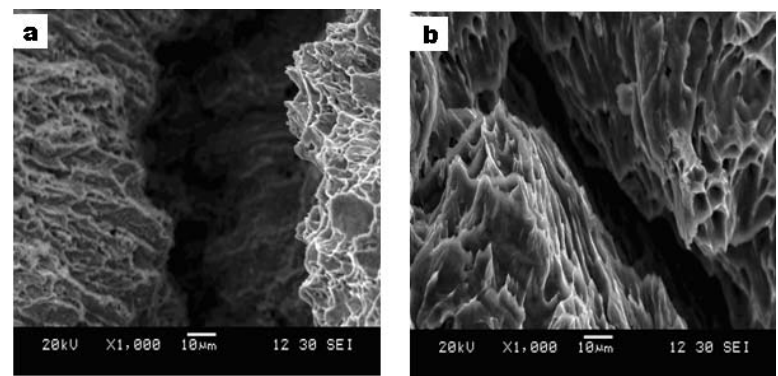

Figure 11: SEM images of fracture surfaces at $100^{\circ} \mathrm{C}$ both show elongated dimples, ductile tearing (a) steel 1045 (b) aluminum 6061.

\section{Conclusions}

Upon completion of their experiments, students understand how alloy steel 1045 and aluminum alloy 6061 changed their behaviour with temperature. Students had the opportunity to observe details of the microstructure of specimens of each alloy and were able to see the differences between behaviour.

Acknowledgement

I wish to thank Dr. Brian Stimpson, university of Manitoba for discussions and assistance with this paper.

\section{References}

Ambrose, S. A., Amon, C, H. "Systematic design of a first-year mechanical engineering course at Carnegie Mellon." Eng. Education 2, no. 86 (1997).

ASTM. Standard Methods for Notched Bar Impact Testing of Metallic Materials. Vol. 03.01. Philadelphia: Annual Book of ASTM Standards, 1984. Shank, M. E. Metallic Materials at Low Temperatures. Vol. 158. ASTM STP, 1953.

ASM. Mechanical Testing. 9. Vol. 8. Ohio: Metals Park, 1985.

ASTM. Standard Method for Notched Bar Impact Testing of Metallic Materials. Philadelphia, PA, USA: American Society for Testing Materials, 1993.

[1] A.B. Smith, C.D. Jones, and E.F. Roberts, "Article Title", Journal, Publisher, Location, Date, pp. 1-10. [2] C.D. Jones, A.B. Smith, and E.F. Roberts, Book Title, Publisher, Location, Date. 